\title{
The Prognostic Value of BMI, Serum Glucose, Endometrial Echo Pattern and Uterine Artery Doppler Velocimetry as a Predictor for Endometrial Pathology in Women with Postmenopausal Bleeding (Prospective Observational Study)
}

\author{
Yehia A. Wafa, Ahmed T. Abd Alfattah, Mohammed Sayed Korany \\ Department of Obstetrics and Gynecology, Faculty of Medicine, Al-Azhar University, Cairo, Egypt \\ Email: egy_77@yahoo.com
}

How to cite this paper: Wafa, Y.A., Abd Alfattah, A.T. and Korany, M.S. (2020) The Prognostic Value of BMI, Serum Glucose, Endometrial Echo Pattern and Uterine Artery Doppler Velocimetry as a Predictor for Endometrial Pathology in Women with Postmenopausal Bleeding (Prospective Observational Study). Open Journal of Obstetrics and Gynecology, 10, 13-24. https://doi.org/10.4236/ojog.2020.101002

Received: October 31, 2019

Accepted: December 28, 2019

Published: December 31, 2019

Copyright $\odot 2020$ by author(s) and Scientific Research Publishing Inc. This work is licensed under the Creative Commons Attribution International License (CC BY 4.0).

http://creativecommons.org/licenses/by/4.0/ (c) (i) Open Access

\section{Abstract}

Background: Post-menopausal bleeding is a warning sign that accounts for about $5 \%$ of all outpatient gynaecologic visits and is a common indication for referral to rapid access clinics because of the fear of underlying malignancy. Endometrial malignancies differ from other malignancies in that early symptomization is common, allowing early cure. Patients and Methods: During the study period, 100 women with post-menopausal bleeding having inclusion criteria were evaluated in Al-Hussein University Hospital. For each patient full history, general, abdominal and pelvic examination was performed. Routine pre-operative investigations were done. Patients were divided into four groups: Group 1 included 29 patients with endometrial polyp. Group 2 included 34 patients with endometrial hyperplasia. Group 3 included 21 patients with atrophic endometrium. Group 4 included 16 patients with endometrial carcinoma. Results: As regards the predictive value of BMI, in the study there was a high statistical significance in comparison between the endometrial carcinoma group and all other benign groups. When discussing the predictive value of blood glucose level, in the study there was a high statistical significance in comparison between the endometrial carcinoma group and all other benign groups. It is worth to mention that the predictive value of endometrial thickness, in the study, was with high statistical significance in comparison between the endometrial carcinoma group and all other benign groups providing the highest specificity and sensitivity. At the last the predic- 
tive value of uterine artery velocimetry, in the study, was with high statistical significance in comparison between the endometrial carcinoma group and all other benign groups. Conclusion: BMI, blood glucose level, endometrial thickness and uterine artery velocimetry indices, improve the prediction of endometrial carcinoma in women with post-menopausal bleeding.

\section{Keywords}

BMI, Serum Glucose, Endometrial Echo Pattern, Uterine Artery Doppler Velocimetry, Endometrial Pathology, Postmenopausal Bleeding

\section{Introduction}

Postmenopausal bleeding (PMB) is defined as bleeding recurring in menopausal women at least 1 year after cessation of cycles [1].

Although PMB may be associated with a number of different conditions, it must always be investigated because many causes are premalignant and malignant. The most common premalignant and malignant causes are complex hyperplasia with atypia and carcinoma of the endometrium. These disorders are present in as many as $1 / 3$ of the patients evaluated for PMB in many series [2].

A large variety of lesions are noted, and the most common single cause is proved to be atrophic vaginitis. It is wisely counselled even though an apparent benign cause of bleeding is found.

Women with PMB deserve a thorough evaluation to rule out malignancy that may also be present [3].

Endometrial cancer usually affects postmenopausal women, and is rare before the age of 40 . Only less than $20 \%$ of endometrial cancers occur before menopause [4].

The risk of endometrial cancer increases with obesity, diabetes, hypertension, nulliparity, hormone replacement therapy and tamoxifen therapy. Increasing age and a family history of hereditary non-polyposis colorectal cancer syndrome are also risk factors for endometrial cancer [5].

Endometrial cancer was among the first cancers identified as being obesity-related [6].

Although the risk of endometrial cancer is slightly increased with type 2 diabetes mellitus this increase is consistent and significant [7].

Transvaginal ultrasound is considered as the initial investigation to diagnose the cause of postmenopausal bleeding [8].

TVUS using a 3-mm cut off has high sensitivity for detecting endometrial cancer and can identify women with PMB who are highly unlikely to have endometrial cancer, thereby avoiding more invasive endometrial biopsy [9].

With the advent of hysteroscopy in the last two decades, focus has shifted from endometrial biopsy to hysteroscopic-guided biopsy as a gold standard diagnostic tool in the evaluation of postmenopausal bleeding [10]. 


\section{Aim of the Work}

This study aims to assess the prognostic value of BMI, serum glucose, endometrial echo pattern and uterine artery Doppler velocimetry as a predictor for endometrial pathology in women with postmenopausal bleeding.

\section{Patients and Methods}

After the study protocol and the whole related documents have been presented for the research ethical committee, Faculty of Medicine, Al-Azhar University. The details of the procedure, aim of the work, benefit and risk of trial have been explained to all patients, this prospective observational study was conducted. During the study period, 100 women with post-menopausal bleeding after fulfilling inclusion criteria at Al-Hussein University Hospital.

Group 1 included 29 patients with endometrial polyp. Group 2 included 34 patients with endometrial hyperplasia. Group 3 included 21 patients with atrophic endometrium. Group 4 included 16 patients with endometrial carcinoma.

The study included menopausal women with natural menopause defined as absence of menstruation for 1 year in women older than 40 years provided that the amenorrhea was not explained by medication or disease or pregnancy. $\mathrm{Pa}$ tients complaining of postmenopausal bleeding and patients with endometrial thickness more than $4 \mathrm{~mm}$ by transvaginal sonography were included.

While patients with bleeding tendency, patients with liver cell failure, patients with congenital anomalies in the uterus, Patients taking anticoagulant drugs as warfarin or heparin, Patients using tamoxifen citrate and patients using any kind of hormonal replacement therapy were excluded from the study.

\subsection{Patient Consent}

All participants signed informed consent (written consent) after explaining benefits and risks of the trial and have the right to leave the study at any time.

All patients are subjected to the following: A-Detailed history: including the following points. Present history of bleeding including onset, course, duration, and criteria of bleeding pattern. History of recent hormonal contraception and particular drug intake. History of bleeding tendency or general cause of bleeding. Past history of operations or blood transfusion. Family history of similar condition. Last menstrual history and amount of bleeding. B-Examination: General examination; Weight, height, general appearance and Body mass index calculation. Body mass index is a measure of body fat based on height and weight that applies to adults, Abbreviated by BMI. BMI is a person's weight in kilograms (kg) divided by his or her height in meters squared.

The following table which is approved by the WHO was applied:

\begin{tabular}{cc}
\hline Meaning & BMI \\
\hline Normal weight & $19-24.9$ \\
Overweight & $25-29.9$ \\
\hline
\end{tabular}


Obesity level I

Obesity level II

Obesity level III

Vital signs (blood pressure and pulse), pallor and manifestations of anaemia. Abdominal examination and Local examination: Inspection of external genitalia. Bimanual examination to detect uterine size, mobility, tenderness and adnexal masses. Speculum examinations for cervical masses, erosions, hypertrophy, ulcers or vaginal lesions. C-Laboratory investigations: Complete blood count. Coagulation profile. Random blood sugar. Liver and kidney functions. D-Ultrasound examination: With an empty bladder, the patient examined in the lithotomy position, Transvaginal ultrasound has been done to study uterine size, endometrial thickness, uterine artery Doppler velocimetry and to exclude any uterine or ovarian pathology. E-Histopathological examination Patients will be subjected to one of the following: Dilatation and curettage-Hysteroscopy with endometrial biopsy.

\subsection{Statistical Analysis}

Recorded data were analyzed using the statistical package for social sciences, version 20.0 (SPSS Inc., Chicago, Illinois, USA). Quantitative data were expressed as mean \pm standard deviation (SD). Qualitative data were expressed as frequency and percentage.

The following tests were done: A one-way analysis of variance (ANOVA) when comparing between more than two means. Post Hoc test: Least Significant Difference (LSD) was used for multiple comparisons between different variables. The confidence interval was set to $95 \%$ and the margin of error accepted was set to $5 \%$. So, the p-value was considered significant as the following: Probability (P-value) $\mathrm{P}$-value $<0.05$ was considered significant. $\mathrm{P}$-value $<0.001$ was considered as highly significant. P-value $>0.05$ was considered insignificant.

\section{Results}

Table 1 shows that women age in years in the study group ranged from $49-80$ with mean $59.78 \pm 6.36$. Table 2 shows that women BMI $\left(\mathrm{kg} / \mathrm{m}^{2}\right)$ in the study group ranged from $20.8-48.8$ with mean $29.84 \pm 6.63$. Table 3 shows that the mean blood glucose level is $136.15 \pm 65.79$ and mean of $\mathrm{HbAlc}$ is $8.13 \pm 1.35$ in the study group population. Table 4 shows that the endometrial thickness of the study group population ranged from $5-25 \mathrm{~mm}$ with mean $11.58 \pm 5.23$. Table 5 shows that the uterine artery peak systolic velocity in the study group population ranged from $2.5-26.5(\mathrm{~cm} / \mathrm{sec})$ with mean $11.17 \pm 4.65$. Table 6 shows the histological types of the biopsies taken from the uterus of the study group population, the number and percentage of each type. Endometrial polyp 29 (29\%), Endometrial hyperplasia without atypia 24 (24\%), Atrophic endometrium 21 
Table 1. Age (years) distribution of the study group.

\begin{tabular}{cc}
\hline Age (years) & Total $(\mathbf{n}=\mathbf{1 0 0})$ \\
\hline Range & $49-80$ \\
Mean $\pm S D$ & $59.78 \pm 6.36$ \\
Median $(I Q R)$ & $60(9)$ \\
\hline
\end{tabular}

Table 2. BMI distribution of the study group.

\begin{tabular}{cc}
\hline BMI $(\mathrm{kg} / \mathrm{M} 2)$ & Total $(\mathbf{n}=100)$ \\
\hline Normal $18.5-25$ & $22(22 \%)$ \\
Overweight $25-30$ & $43(43 \%)$ \\
Obese $>30$ & $35(35 \%)$ \\
Range $[$ Mean $\pm S D]$ & $20.8-48.8[29.84 \pm 6.63]$ \\
\hline
\end{tabular}

Table 3. Blood glucose level and HbAlc descriptive of the patients group.

\begin{tabular}{cc}
\hline & Total $(\mathbf{n}=100)$ \\
\hline Blood glucose level & $70-377$ \\
Range & $136.15 \pm 65.79$ \\
Mean $\pm S D$ & \\
HbAlc & $5.7-10.9$ \\
Range & $8.13 \pm 1.35$ \\
Mean $\pm S D$ &
\end{tabular}

Table 4. Endometrial thickness descriptive of the patients group.

\begin{tabular}{cc}
\hline Endometrial thickness $(\mathrm{mm})$ & Total $(\mathrm{n}=100)$ \\
\hline Range & $5-25$ \\
Mean $\pm S D$ & $11.58 \pm 5.23$ \\
\hline
\end{tabular}

Table 5. Uterine artery peak systolic velocity descriptive of the patients group.

\begin{tabular}{cc}
\hline Uterine artery peak systolic velocity $(\mathrm{cm} / \mathrm{S})$ & Total $(\mathrm{n}=100)$ \\
\hline Rt uterine artery peak systolic velocity $(\mathrm{cm} / \mathrm{s})$ & $3-27$ \\
Mean $\pm S D$ & $11.13 \pm 4.67$ \\
Range & $2-26$ \\
Mean $\pm S D$ & $11.22 \pm 4.69$ \\
Rt Uterine artery peak systolic velocity $(\mathrm{cm} / \mathrm{S})$ & \\
Uterine artery peak systolic velocity $(\mathrm{cm} / \mathrm{S})$ & $2.5-26.5$ \\
Mean $\pm S D$ & $11.17 \pm 4.65$ \\
\hline
\end{tabular}


(21\%), Endometrial carcinoma $16(16 \%)$ and Endometrial hyperplasia with atypia $10(10 \%)$ of histopathology. Table 7 shows that there is no statistically significant difference between histopathology and age (years) of the study group. However Table 8 that compares between histopathology and BMI of the study group population shows statistically significant difference between histopathology of benign lesions and malignant lesions with increasing BMI in the study group. Also Table 9 shows statistically significant difference between histopathology of benign lesions and malignant lesions with increasing blood glucose level and HbA1c in the study group. Table 10 shows statistically significant difference between histopathology of benign lesions and malignant lesions with increasing endometrial thickness in the study group. As most of the later indices Table 11 shows statistically significant difference between histopathology of benign lesions and malignant lesions with increasing uterine artery peak systolic velocity $(\mathrm{cm} / \mathrm{S})$ in the study group. Table 12 shows the different parameter indices for endometrial carcinoma.

Figure 1 shows Receiver operator characteristics (ROC) curves constructed for parameters indices of endometrial carcinoma [Endometrial thickness ( $\mathrm{mm})$, Rt uterine artery peak systolic velocity $(\mathrm{cm} / \mathrm{s})$, Lt Uterine artery peak systolic velocity $(\mathrm{cm} / \mathrm{S})$ and Uterine artery peak systolic velocity $(\mathrm{cm} / \mathrm{S})]$ as predictors of endometrial carcinoma in included women. All items indices were significant

Table 6. Histopathology distribution of the patients group.

\begin{tabular}{cc} 
Histopathology & Total (n=100) \\
\hline Endometrial polyp & $29(29 \%)$ \\
Endometrial hyperplasia without atypia & $24(24 \%)$ \\
Atrophic endometrium & $21(21 \%)$ \\
Endometrial carcinoma & $16(16 \%)$ \\
Endometrial hyperplasia with atypia & $10(10 \%)$
\end{tabular}

Table 7. Comparison between histopathology and age (years) of the study group.

\begin{tabular}{ccccccc}
\hline Age (years) & $\begin{array}{c}\text { Atrophic } \\
\text { endometrium } \\
(n=21)\end{array}$ & $\begin{array}{c}\text { Endometrial Endometrial } \\
\text { polyp } \\
(n=29)\end{array}$ & $\begin{array}{c}\text { Eyperplasia } \\
\text { hy=34) }\end{array}$ & $\begin{array}{c}\text { carcinoma } \\
(n=16)\end{array}$ & ANOVA & p-value \\
\hline Mean \pm SD & $60.24 \pm 5.09$ & $58.48 \pm 6.66$ & $58.79 \pm 6.08$ & $63.63 \pm 6.82$ & & \\
Range & $51-70$ & $49-73$ & $49-69$ & $50-80$ & 1.808 & 0.144
\end{tabular}

Table 8. Comparison between histopathology and BMI of the study group.

\begin{tabular}{|c|c|c|c|c|c|c|}
\hline BMI (kg/M2) & $\begin{array}{c}\text { Atrophic } \\
\text { endometrium } \\
(n=21)\end{array}$ & $\begin{array}{c}\text { Endometrial } \\
\text { polyp } \\
(n=29)\end{array}$ & $\begin{array}{l}\text { Endometrial } \\
\text { hyperplasia } \\
\quad(n=34)\end{array}$ & $\begin{array}{l}\text { Endometrial } \\
\text { carcinoma } \\
(n=16)\end{array}$ & ANOVA & $\mathrm{p}$-value \\
\hline Mean $\pm S D$ & $27.85 \pm 3.59$ & $26.32 \pm 3.95$ & $30.20 \pm 5.44 \mathrm{ab}$ & $38.07 \pm 8.76 \mathrm{abc}$ & \multirow{2}{*}{17.346} & \multirow{2}{*}{$<0.001^{\star x}$} \\
\hline Range & $22.5-34.2$ & $20.8-39$ & $20.8-40.6$ & $22.2-48.8$ & & \\
\hline
\end{tabular}


Table 9. Comparison between histopathology and blood glucose level and HbA1c of the study group.

\begin{tabular}{|c|c|c|c|c|c|c|}
\hline & $\begin{array}{c}\text { Atrophic } \\
\text { endometrium }(n=21)\end{array}$ & $\begin{array}{l}\text { Endometrial polyp } \\
\qquad(n=29)\end{array}$ & $\begin{array}{c}\text { Endometrial } \\
\text { hyperplasia }(n=34)\end{array}$ & $\begin{array}{c}\text { Endometrial } \\
\text { carcinoma }(n=16)\end{array}$ & ANOVA & p-value \\
\hline \multicolumn{7}{|c|}{ Blood glucose level } \\
\hline Mean \pm SD & $103.71 \pm 25.43$ & $110.28 \pm 27.49$ & $140.85 \pm 66.11 \mathrm{ab}$ & $215.63 \pm 84.42 \mathrm{abc}$ & \multirow[b]{2}{*}{16.078} & \multirow[b]{2}{*}{$<0.001^{\star *}$} \\
\hline Range & $77-189$ & $70-189$ & $78-290$ & $95-377$ & & \\
\hline \multicolumn{7}{|l|}{ HbAlc } \\
\hline Mean \pm SD & $7.30 \pm 0$ & $6.43 \pm 0.53 a$ & $7.73 \pm 0.76 b$ & $9.04 \pm 1.31 \mathrm{abc}$ & \multirow{2}{*}{8.066} & \multirow{2}{*}{$<0.001^{\star *}$} \\
\hline Range & $7.3-7.3$ & $5.7-6.9$ & $6.7-9.1$ & $7.1-10.9$ & & \\
\hline
\end{tabular}

Table 10. Comparison between histopathology and endometrial thickness $(\mathrm{mm})$ of the study group.

\begin{tabular}{ccccccc}
\hline $\begin{array}{c}\text { Endometrial } \\
\text { thickness }(\mathrm{mm})\end{array}$ & $\begin{array}{c}\text { Atrophic endometrium } \\
(\boldsymbol{n}=\mathbf{2 1})\end{array}$ & $\begin{array}{c}\text { Endometrial polyp } \\
(\boldsymbol{n}=\mathbf{2 9})\end{array}$ & $\begin{array}{c}\text { Endometrial } \\
\text { hyperplasia }(\boldsymbol{n}=\mathbf{3 4 )})\end{array}$ & $\begin{array}{c}\text { Endometrial } \\
\text { carcinoma }(\boldsymbol{n}=16)\end{array}$ & ANOVA & p-value \\
\hline Mean $\pm \mathrm{SD}$ & $5.43 \pm 0.68$ & $10.31 \pm 2.94 \mathrm{a}$ & $12.94 \pm 3.82 \mathrm{ab}$ & $19.06 \pm 3.43 \mathrm{abc}$ & 63.292 & $<0.001^{* *}$ \\
Range & $5-7$ & $6-17$ & $8-21$ & $12-25$ & \\
\hline
\end{tabular}

Table 11. Comparison between histopathology and uterine artery peak systolic velocity $(\mathrm{cm} / \mathrm{S})$ of the study group.

\begin{tabular}{|c|c|c|c|c|c|c|}
\hline $\begin{array}{c}\text { Uterine artery peak } \\
\text { systolic velocity }(\mathrm{cm} / \mathrm{S})\end{array}$ & $\begin{array}{c}\text { Atrophic } \\
\text { endometrium }(n=21)\end{array}$ & $\begin{array}{l}\text { Endometrial } \\
\text { polyp }(n=29)\end{array}$ & $\begin{array}{c}\text { Endometrial } \\
\text { hyperplasia }(n=34)\end{array}$ & $\begin{array}{c}\text { Endometrial } \\
\text { carcinoma }(n=16)\end{array}$ & ANOVA & p-value \\
\hline \multicolumn{7}{|l|}{$\begin{array}{c}\text { Rt uterine artery } \\
\text { peak systolic velocity }(\mathrm{cm} / \mathrm{s})\end{array}$} \\
\hline $\begin{array}{c}\text { Mean } \pm \text { SD } \\
\text { Range }\end{array}$ & $\begin{array}{c}8.48 \pm 2.54 \\
4-15\end{array}$ & $\begin{array}{c}10.86 \pm 5.13 a \\
3-19\end{array}$ & $\begin{array}{c}10.62 \pm 2.45 a \\
6-17\end{array}$ & $\begin{array}{c}16.19 \pm 5.90 \mathrm{abc} \\
9-27\end{array}$ & 11.455 & $<0.001^{* *}$ \\
\hline \multicolumn{7}{|l|}{$\begin{array}{c}\text { Lt Uterine artery } \\
\text { peak systolic velocity }(\mathrm{cm} / \mathrm{S})\end{array}$} \\
\hline $\begin{array}{c}\text { Mean } \pm \text { SD } \\
\text { Range }\end{array}$ & $\begin{array}{c}8.81 \pm 2.69 \\
5-15\end{array}$ & $\begin{array}{c}10.90 \pm 5.08 \mathrm{a} \\
2-20\end{array}$ & $\begin{array}{c}10.68 \pm 3.07 \mathrm{a} \\
2-18\end{array}$ & $\begin{array}{c}16.13 \pm 5.64 a b c \\
9-26\end{array}$ & 10.042 & $<0.001^{\star *}$ \\
\hline \multicolumn{7}{|l|}{$\begin{array}{c}\text { Uterine artery } \\
\text { peak systolic velocity }(\mathrm{cm} / \mathrm{S})\end{array}$} \\
\hline $\begin{array}{c}\text { Mean } \pm \text { SD } \\
\text { Range }\end{array}$ & $\begin{array}{c}8.64 \pm 2.59 \\
4.5-15\end{array}$ & $\begin{array}{c}10.88 \pm 5.08 \mathrm{a} \\
2.5-19.5\end{array}$ & $\begin{array}{c}10.62 \pm 2.72 \mathrm{a} \\
5-17.5\end{array}$ & $\begin{array}{c}16.16 \pm 5.75 a b c \\
9-26.5\end{array}$ & 10.903 & $<0.001^{* *}$ \\
\hline
\end{tabular}

Table 12. The different parameter indices for endometrial carcinoma.

\begin{tabular}{cccccccc}
\hline Items & Cut-off & Sen. & Spec. & PPV & NPV & Accuracy & p-value \\
\hline Endometrial thickness $(\mathrm{mm})$ & $>14$ & $87.5 \%$ & $84.5 \%$ & $51.9 \%$ & $97.3 \%$ & $94.1 \%$ & $<0.001^{* *}$ \\
Rt uterine artery peak systolic velocity $(\mathrm{cm} / \mathrm{s})$ & $>15$ & $56.3 \%$ & $89.3 \%$ & $50.0 \%$ & $91.5 \%$ & $79.6 \%$ & $<0.001^{* *}$ \\
Lt Uterine artery peak systolic velocity $(\mathrm{cm} / \mathrm{S})$ & $>13$ & $62.5 \%$ & $83.3 \%$ & $41.7 \%$ & $92.1 \%$ & $79.3 \%$ & $<0.001^{* *}$ \\
Uterine artery peak systolic velocity $(\mathrm{cm} / \mathrm{S})$ & $>15$ & $56.3 \%$ & $88.1 \%$ & $47.4 \%$ & $91.4 \%$ & $79.6 \%$ & $<0.001^{* *}$ \\
\hline
\end{tabular}

predictors as denoted by the significantly large area under the curves (AUCs); with endometrial thickness being the most significant predictor. 


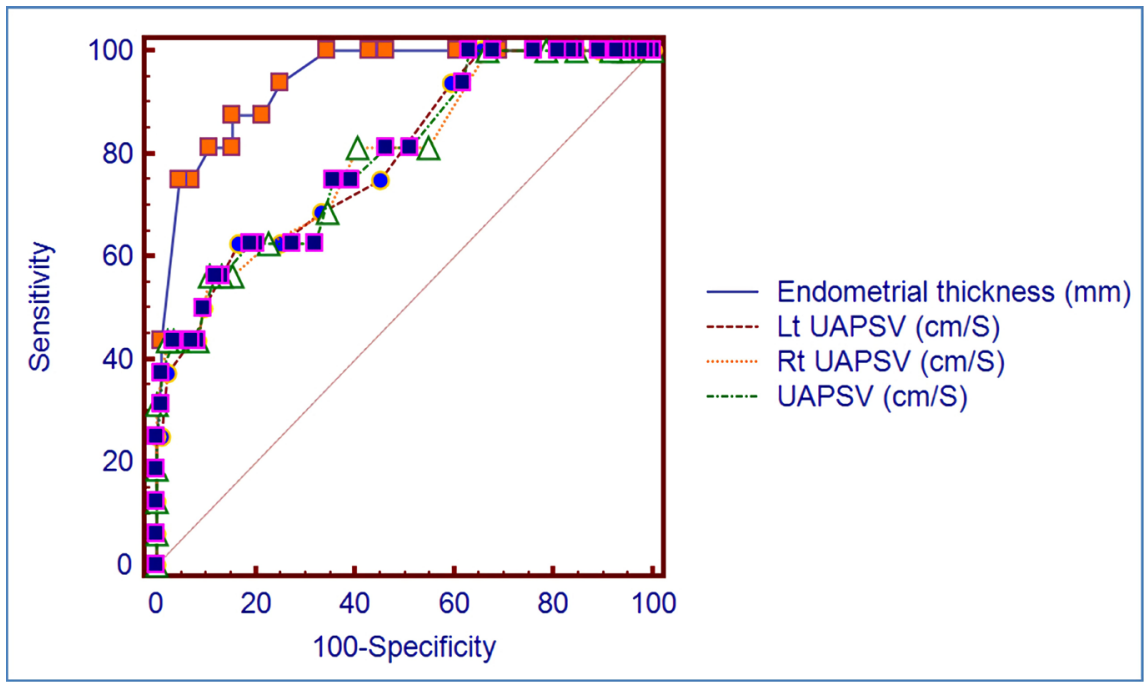

Figure 1. Receiver-operating characteristic (ROC) curve for prediction of endometrial carcinoma using the endometrial thickness and uterine artery peak systolic velocity.

\section{Discussion}

Endometrial cancer is the most common malignancy of the female genital tract in developed countries. Unlike other malignancies, endometrial cancer often presents at an early stage when there is a possibility of curative treatment by Hysterectomy. Survival decreases with increased staging and lower histological differentiation, thus accurate and timely diagnosis is important and should preferably be carried out by a safe, simple and minimally invasive method [11].

In the modern era transvaginal ultrasound is considered as the first line approach and has been replaced dilatation and curettage as a first line [12].

Transvaginal ultrasound may have predictive value for endometrial cancer among post-menopausal women. Meta-analysis of 5892 symptomatic women (i.e., with postmenopausal bleeding) in 35 published studies showed that an endometrial thickness of $5 \mathrm{~mm}$ or greater identified $95 \%$ of all endometrial cancers. Conversely, in this population, women with an endometrial thickness of less than $4 \mathrm{~mm}$ had only a $1 \%$ probability of cancer. Among post-menopausal women, endometrium thickness $>1 \mathrm{~cm}$ as assessed by transvaginal ultrasound is correlated with an increased risk of endometrial cancer [13].

This study aims to assess the accuracy of BMI, level of blood glucose, endometrial echo pattern and uterine artery velocimetry in prediction of endometrial cancer in women with postmenopausal bleeding in comparison with histopathology. This prospective observational study conducted on 107 with post-menopausal bleeding and endometrial thickness $\geq 4 \mathrm{~mm}$ were potentially eligible for inclusion in our study. During the study period, 100 women with postmenopausal bleeding were evaluated, five patients were excluded due to power Doppler artefacts and very poor image quality and two were excluded to histopathology result of insufficient sample.

One hundred women were included; patient mean age was 59.78 years (range 
49 - 80 years). Mean body mass index BMI was 29.84 (range 20.8 - 48.8). patient mean blood glucose level was 136.15 (range 70 - 377 mg/dl). Mean endometrial thickness was 11.42 (range 4 - 25). Mean uterine artery peak systolic velocity was 11.17 (range $2.5-26.5 \mathrm{~cm} / \mathrm{sec}$ ). Histopathological diagnosis were endometrial cancer (16 cases; 16\%), endometrial hyperplasia with atypia (10 cases; $10 \%)$, endometrial hyperplasia without atypia (24 cases; $24 \%$ ), endometrial polyp (29 cases; $29 \%$ ) and atrophic endometrium was (21 cases; $21 \%$ ).

As regarding body mass index (BMI) the study shows that BMI was statistically significant lower in patients with benign lesions. BMI was the same in patients with polyp (mean $26.32 \pm 3.95$ ) and atrophic endometrium (mean $27.85 \pm$ 3.59). However BMI was higher in patients with endometrial hyperplasia (mean $30.20 \pm 5.44)$.

As regarding blood glucose level the study shows that blood glucose level was statistically significant lower in patients with benign lesions. Blood glucose level was nearly the same in patients with polyp (mean 110.28 \pm 27.49 ) and atrophic endometrium (mean $103.71 \pm 25.43$ ). However blood glucose level was higher in patients with endometrial hyperplasia (mean $140.85 \pm 66.11$ ).

As regarding endometrial thickness the study shows that endometrial thickness was statistically significant lower in patients with benign lesions. Endometrial thickness was nearly the same in patients with polyp (mean $10.31 \pm 2.94$ ) and endometrial hyperplasia (mean $12.94 \pm 3.82$ ) .However endometrial thickness in patients with atrophic endometrium was (mean $4.67 \pm 1.28$ ) this was less than other benign lesions. Endometrial thickness less than $5 \mathrm{~mm}$ was associated always with atrophic endometrium. However there was overlap between cases who have benign or malignant lesions. The best cut-off for diagnosis of carcinoma was $>14 \mathrm{~mm}$ with sensitivity of $87.5 \%$ and specificity $84.5 \%$.

As regarding the uterine artery peak systolic velocimetry; the study shows that uterine artery peak systolic velocimetry was statistically significant lower in patients with benign lesions. Uterine artery peak systolic velocimetry was nearly the same in patients with polyp (mean $10.88 \pm 5.08$ ) and endometrial hyperplasia (mean $10.62 \pm 2.72$ ). However uterine artery peak systolic velocimetry in patients with atrophic endometrium was (mean $8.64 \pm 2.59$ ); this was less than other benign lesions. The best cut-off for diagnosis of carcinoma was >15 $\mathrm{cm} / \mathrm{sec}$ with sensitivity of $56.3 \%$ and specificity $88.1 \%$.

Revision of the published literature revealed many studies assessing the prediction of endometrial carcinoma through BMI, blood glucose level or the presence of medical condition i.e., Diabetes, endometrial thickness and uterine increased vascularization however none of them took all our variables in one study.

A similar prospective observational study that was conducted by [12] included 165 women with post-menopausal bleeding addressing the correlation of clinical characteristics with histopathological pattern of endometrium in the prediction of endometrial carcinoma in women with post-menopausal bleeding and concluded similar results to our study regarding the clinical significance between the presence of diabetes, increased BMI and increased endometrial thickness and 
the prediction of endometrial cancer in post-menopausal women. This similarity may be attributed to the relative small number of both studies.

Another prospective observational study that agreed was our study conducted by [14] regarding the prediction value of the endometrial thickness and vascular indices in predicting malignancy in postmenopausal women with vaginal bleeding. Although they used in their study over the 174 women they chose, the 2D/3D power Doppler the final conclusion of that the increased endometrial vascularity can positively predict endometrial malignancy still can support the results of our study.

[15] agreed with our study regarding the clinically significant correlation between diabetes \& obesity and endometrial cancer after conducted a large population based prospective cohort study that included 36,773 women, 225 endometrial cancer patients was diagnosed. This study contained many variables diabetes and obesity (increased BMI) were among these variables. [15] suggested that women with diabetes had a statistically significant $\sim 2$ fold higher risk for developing endometrial cancer. This risk was increased $>6$ fold among obese diabetic women compared with normal weight women without diabetes.

Another study [16] agreed with our study in the predictive value of endometrial thickness and increased endometrial vascularity indices using power Doppler ultrasound after conducting a small study in Sweden over 83 postmenopausal women with vaginal bleeding.

[17] who developed a risk scoring model including recurrent vaginal bleeding, endometrial thickness $>8 \mathrm{~mm}$, presence of hypertension, and age $>65$ called RHEA, which provided a moderate diagnostic accuracy for the prediction of intrauterine malignancies among post-menopausal women at risk of endometrial cancer, agreed with us about the predictive value of endometrial thickness. However he disagreed with our study in the value of BMI and diabetes in the prediction of endometrial cancer in postmenopausal women suffering of post-menopausal bleeding.

\section{Conclusion}

BMI, blood glucose level, endometrial thickness and uterine artery velocimetry indices, improve the prediction of endometrial carcinoma in women with postmenopausal bleeding. It is worth to mention that the endometrial thickness was the most accurate variable; however the small number included in this study limits its value although it's supported by the results of similar studies giving the conclusions. Larger studies may be carried on the same indices to confirm that results aiming to develop a risk scoring model provide high diagnostic accuracy for the prediction of intrauterine malignancies among post-menopausal women.

\section{Conflicts of Interest}

The authors declare no conflicts of interest regarding the publication of this paper. 


\section{References}

[1] Sperrof, L. and Fritz, M. (2005) Part II: Clinical Endocrinology. Chapter 15: Dysfunctional Uterine Bleeding: Endometrial Hyperplasia and Neoplasia in Clinical Gynecologic Endocrinology \& Infertility. 6th Edition, Lippincott Williams \& Wilkins, Philadelphia, 561.

[2] Ferri, F.F. (2011) Differential Diagnosis. A Practical Guide to Differential of Symptoms, Signs, and Clinical Disorders. Mosby, London, 1184. https://doi.org/10.1016/B978-0-323-07158-1.00002-X

[3] Lentz, G.M., Katz, V.L., Lobo, R.A. and Gershenson, D.M. (2007) Diagnostic Procedures-Imaging, Endometrial Sampling, and Endoscopy: Indications and Contraindications, Complications. In: Comprehensive Gynecology, 5th Edition, MOSPY Elsevier, Philadelphia, Chapter 11, 215-220.

[4] Engelsen, I.B., Akslen, L.A. and Salvesen, H.B. (2009) Biologic Markers in Endometrial Cancer Treatment. APMIS, 117, 693-707.

https://www.ncbi.nlm.nih.gov/pubmed/19775337 https://doi.org/10.1111/j.1600-0463.2009.02467.x

[5] Amant, F., Moerman, P., Neven, P., Timmerman, D., Van Limbergen, E. and Vergote, I. (2005) Endometrial Cancer. The Lancet, 366, 491-505. https://doi.org/10.1016/S0140-6736(05)67063-8

[6] Gifkins, D.M., Bandera, E.V., Kushi, L.H., Moore, D.F. and McCullough, M.L. (2007) The Association between Food, Nutrition, and Physical Activity and the Risk of Endometrial Cancer and Underlying Mechanisms. World Cancer Research Fund/American Institute for Cancer Research Second Report on Food, Nutrition, Physical Activity and the Prevention of Cancer, The Cancer Institute of New Jersey. https://www.ncbi.nlm.nih.gov/pmc/articles/PMC2214669

[7] Liao, C., Zhang, D., Mungo, C., Tompkins, D.A. and Zeidan, A.M. (2014) Is Diabetes Mellitus Associated with Increased Incidence and Disease Specific Mortality in Endometrial Cancer? A Systematic Review and Meta-Analysis of Cohort Studies. Gynecologic Oncology, 135, 163-171. https://doi.org/10.1016/j.ygyno.2014.07.095 https://www.ncbi.nlm.nih.gov/pmc/articles/PMC4404750

[8] Oehelr, M.K., Mackenzie, I., Kehoe, S. and Rees, M.C. (2003) Assessment of Abnormal Bleeding in Menopausal Women: An Update. Obstetrical \& Gynecological Survey, 59, 369-378. https://www.ncbi.nlm.nih.gov/pubmed/14670197

[9] Wong, A.W., Lao, T.H., Cheung, C.W., Yeung, S.W., Fan, H.L., Ng, P.S., Yuen, P.M. and Sahota, D.S. (2016) Reappraisal of Endometrial Thickness for the Detection of Endometrial Cancer in Postmenopausal Bleeding: A Retrospective Cohort Study. BJOG, 123, 439-446. https://doi.org/10.1111/1471-0528.13342 https://obgyn.onlinelibrary.wiley.com/doi/full/10.1111/1471-0528.13342

[10] Van Dongen, H., de Kroon, C.D., Jacobi, C.E., Trimbos, J.B. and Jansen, F.W. (2007) Diagnostic Hysteroscopy in Abnormal Uterine Bleeding: A Systematic Review and Meta-Analysis. BJOG, 114, 664-675.

https://www.ncbi.nlm.nih.gov/pubmed/17516956 https://doi.org/10.1111/j.1471-0528.2007.01326.x

[11] Breijer, M., Timmermans, A., van Doorn, H., Mol, W. and Opmeer, B. (2010) Diagnostic Strategies for Postmenopausal Bleeding. Obstetrics and Gynecology International, 2010, Article ID: 850812. https://doi.org/10.1155/2010/850812 https://www.researchgate.net/publication/41487803_Diagnostic_Strategies_for_Post menopausal_Bleeding

[12] Archana, S. and Syamala, O. (2018) Correlation of Clinical Characteristics with 
Histopathological Pattern of Endometrium in the Prediction of Endometrial Cancer in Postmenopausal Bleeding. IOSR Journal of Dental and Medical Sciences, 17, $52-58$.

https://www.iosrjournals.org/iosr-jdms/papers/Vol17-issue12/Version-2/J17120252 58.pdf

[13] Trimble, C.L., Method, M., Leitao, M., Lu, K., Ioffe, O., Hampton, M., Higgins, R., Zaino, R. and Mutter, G.L. (2012) Management of Endometrial Precancers. Obstetrics \& Gynecology, 120, 1160-1175.

https://www.ncbi.nlm.nih.gov/pubmed/23090535

[14] Kim, A., Lee, J.Y., Chun, S. and Kim, H.Y. (2015) Diagnostic Utility of Three-Dimensional Power Doppler Ultrasound for Postmenopausal Bleeding. Taiwanese Journal of Obstetrics \& Gynecology, 54, 221-226.

https://www.sciencedirect.com/science/article/pii/S1028455915000686 https://doi.org/10.1016/j.tjog.2013.10.043

[15] Friberg, E., Mantzoros, C.S. and Wolk, A. (2007) Population-Based Prospective Cohort Study Diabetes and Risk of Endometrial Cancer. Cancer Epidemiology, Biomarkers \& Prevention, 16, 276-280. https://doi.org/10.1158/1055-9965.EPI-06-0751 https://cebp.aacrjournals.org/content/cebp/16/2/276.full.pdf

[16] Epstein, E., Skoog, L., Isberg, P.E., De Smet, F., De Moor, B., Olofsson, P.A., Gudmundsson, S. and Valentin, L. (2002) An Algorithm Including Results of Gray-Scale and Power Doppler Ultrasound Examination to Predict Endometrial Malignancy in Women with Postmenopausal Bleeding. Ultrasound in Obstetrics \& Gynecology, 20, 370-376. https://doi.org/10.1046/j.1469-0705.2002.00800.x https://obgyn.onlinelibrary.wiley.com/doi/pdf/10.1046/j.1469-0705.2002.00800

[17] Giannella, L., Mfuta, K., Setti, T., Cerami, L.B., Bergamini, E. and Boselli, F. (2014) A Risk-Scoring Model for the Prediction of Endometrial Cancer among Symptomatic Postmenopausal Women with Endometrial Thickness $>4 \mathrm{~mm}$. BioMed Research International, 2014, Article ID: 130569. https://www.hindawi.com/journals/bmri/2014/130569/cta https://doi.org/10.1155/2014/130569 